\title{
O psicólogo nos Núcleos de Apoio à Saúde da Família: organização e condições de trabalho
}

Maria do Socorro Roberto de Lucena. Universidade Federal da Paraíba

Thaís Augusta Cunha de Oliveira Máximo. Universidade Federal da Paraíba

\section{Resumo}

Com a criação do Núcleo de Apoio à Saúde da Família (NASF), os psicólogos são inseridos oficialmente na atenção básica. Este estudo, portanto, teve como objetivo analisar a organização e condições de trabalho de psicólogos dos NASFs. Participaram da pesquisa, sete psicólogos, com idades entre 29 e 53 anos, sendo a maioria do sexo feminino. Os resultados mostraram que estes profissionais desempenham o apoio assistencial e técnico-pedagógico e a função de administradores das unidades. Os participantes ainda destacaram que enfrentam dificuldades na relação com os supervisores, principalmente no que diz respeito à autonomia. Ademais relataram ter que trabalhar em meio a condições de trabalho precárias e, além disso, sob fortes pressões. As reflexões e conclusões deste estudo nos remetem para a urgência de dar uma maior visibilidade à atividade dos psicólogos na atenção básica, atentando para as questões do trabalho e como isso reverbera no serviço prestado.

Palavras-chave: psicologia; nasf; trabalho; subjetividade.

\begin{abstract}
The psychologist in the Family Health Support Center: organization and working conditions. With the creation of the Family Health Support Center (NASF - in Portuguese), psychologists are officially included in basic health care. This study, therefore, aimed to analyze the organization and working conditions of NASF psychologists. The research included seven psychologists, aged between 29 and 53 years, the majority being female. The results showed that these professionals play the role of support, technical-pedagogical support, as well as the function of administrators of the health units. Participants also pointed out that they face difficulties on their relationship with supervisors, especially regarding autonomy. They also reported having to work amid precarious working conditions and, in addition, under heavy pressure. The reflections and conclusions of this study point to the need to give greater visibility to the activity of the supporting psychologists, paying attention to the issues of work and how this reverberates in the service provided.
\end{abstract}

Keywords: psychology; NASF; work; subjectivity.

\section{Resumen}

Lo psicólogo en los Centros de Apoyo a la Salud de la Familia: organización y las condiciones de trabajo. Con la creación de lo Núcleo de Apoyo a Salud de la Familia (NASF), los psicólogos son oficialmente insertados en la política de atención básica a la salud. Este estudio, por lo tanto, tenía como objetivo analizar la organización y condiciones de trabajo de los psicólogos en los NASF. Participaron de esta investigación siete psicólogos, con edades entre 29 y 53 años, la mayoría de sexo femenino. Los resultados demostraron que estos profesionales desempeñan apoyo asistencial y técnico-pedagógico, y también el cargo de administradores de las unidades de salud. Los participantes también señalaron que enfrentan dificultades en su relación con los supervisores, principalmente con relación a su autonomía profesional. Informaron aún que les toca trabajar en condiciones precarias, además de sufrir fuertes presiones. Las reflexiones y conclusiones de este artículo remiten para la urgencia de ofrecer una mayor visibilidad a la actividad de los psicólogos apoyadores, prestándoles atención a los aspectos de trabajo y como estos reverberas en el servicio prestado.

Palabras-clave: psicología; NASF; trabajo; subjetividad. 
Atualmente, os serviços e ações desenvolvidas na atenção básica no Brasil são conduzidos pela Estratégia Saúde da Família (ESF). A equipe mínima da ESF é formada pelos seguintes profissionais: médico, enfermeiro, técnico e auxiliar de enfermagem, agente comunitário de saúde, cirurgião dentista, técnico e auxiliar em saúde bucal (Ministério da Saúde [MS], 2012). Com o intuito de ampliar a abrangência do cuidado e a resolutividade da ESF, o Ministério da Saúde, através da Portaria $\mathrm{n}^{\circ} 154$, de 24 de janeiro de 2008, cria o Núcleo de Apoio à Saúde da Família - NASF (Garcia \& Nascimento, 2012).

O NASF, portanto, tem como objetivo final prestar retaguarda assistencial e técnico-pedagógica às Equipes da Estratégia Saúde da Família (EqSF), através da formação de uma rede de compartilhamento e corresponsabilização entre os dois serviços, ou seja, o matriciamento. Além disso, com o estabelecimento deste dispositivo de apoio, diferentes profissionais/saberes: assistentes sociais, nutricionistas, fisioterapeutas, psicólogos e outros, passam a fazer parte oficialmente da produção do cuidado na atenção básica. (MS, 2012).

Desse modo, a criação do NASF é uma importante estratégia para a reestruturação dos modelos de produção de saúde, uma vez que há a diversificação dos olhares sobre os problemas de saúde-doença. Outrossim, institucionaliza o apoio matricial e o matriciamento como ferramentas de trabalho na atenção básica, impactando assim, o núcleo tecnológico dos processos de trabalho das equipes, haja vista, a necessidade destas, de desenvolverem um trabalho pautado em relações horizontais de troca, compartilhamento, aprendizado e construção, se distanciando de processos de trabalho centrados na fragmentação e mecanização das ações (Bispo Júnior \& Moreira, 2017; Franco \& Merhy, 2012).

Nesse sentido, acredita-se que a inserção do(a) psicólogo(a) nesse espaço, contribui, sobretudo, no que diz respeito ao auxílio e capacitação das EqSF na identificação e no lidar com as questões de saúde mental, sejam elas provenientes da comunidade ou dos profissionais.

Entretanto, a contribuição aqui enfatizada e requerida não se refere a uma prática clínica tradicional, em que a preocupação principal dos profissionais seria os aspectos intrapsíquicos e a psicoterapia (Azevedo \& Kind, 2013).

A este respeito, o texto da Portaria traz claramente que as ações de saúde mental, devem situar-se na proposta de atenção psicossocial, independente da formação específica de cada profissional. Portanto, espera-se que o(a) psicólogo(a) tenha uma prática condizente com uma visão ampliada da relação sujeito e sociedade, em que a ideia de coletividade deva prevalecer no desenvolvimento de suas ações (Freire \& Pichelli, 2013).

Em relação aos que compõem esse eixo de saber do NASF, a prescrição é de que devem atender os usuários e familiares que estejam em situação de risco psicossocial ou doença mental, visando favorecer o acesso ao sistema de saúde e a inserção social. Isso inclui desenvolver ações para combater, prevenir o sofrimento pessoal/familiar associado a qualquer condição física, mental, subjetiva e social, mobilizando também recursos comunitários (Moreira \& Castro, 2009).

Contudo, sabe-se que os psicólogos têm enfrentado algumas dificuldades, quando inseridos nas políticas públicas de saúde, primeiramente, porque a ciência psicológica é bastante diversa, são muitas abordagens, cada uma como sua forma de enxergar o ser humano e a relação deste com o mundo, em segundo lugar, apesar de algumas mudanças, a formação oferecida aos psicólogos ainda deixa a desejar no que diz respeito à preparação desses profissionais para a identificação de alteridades, ou na facilitação do desenvolvimento de sua capacidade crítica, argumentativa e administrativa, (Silveira, Gewehr, Bonin, \& Bulgacov, 2008).

Essa conjuntura tem sido evidenciada pela produção científica nacional dos últimos anos. Em pesquisa realizada nas bases de dados SciELO (Scientific Eletronic Library ) e Lilacs (Literatura Latino-americana do Caribe em Ciências da Saúde), estudos como os de Azevedo e Kind (2013); Boing e Crepaldi (2010); Camargo-Borges e Cardoso (2005); Cézar, Rodrigues e Arpini (2015); Giacomozzi (2012); Freire e Pichelli (2013); Goraybe, Borges e Oliveira (2012); Leite, Andrade e Bosi (2013), problematizam a inserção dos psicólogos na Estratégia Saúde da Família, via NASF. É unanimidade nos estudos, a consideração da importância deste profissional para a consolidação do cuidado nesse nível de atenção à saúde, mas também a preocupação com os impactos e necessidades geradas por essas novas experiências de trabalho para os profissionais.

Ademais, os psicólogos passam a fazerem parte de uma complexa realidade de trabalho. A prática na ESF, coloca os profissionais em contato direto com comunidades em situação de vulnerabilidade(s), o que os leva a ter que lidar com problemas relacionados à pobreza, violência, drogas, que interferem na qualidade da saúde da população e a solução escapa à capacidade do profissionais ou da equipe. Além do mais, existem limites e dificuldades 
geradas pela precariedade do trabalho no setor público (Katsurayama, Parente, Moraes, \& Moretti, 2013).

Soma-se a isso, mudanças nos modelos de gestão, haja vista, a intensa racionalização dos recursos no setor de saúde para enfrentar os gastos, o que leva a intensificação do trabalho e colocação dos trabalhadores de saúde no meio de dilemas: ter que prestar um atendimento em um curto tempo, fazendo uso do mínimo de recursos. (Assunção \& Filho, 2011).

Assim, este artigo tem como objetivo analisar a organização e condições de trabalho de psicólogos dos NASFs. Para tanto, utilizou-se como respaldo teórico à Psicodinâmica do Trabalho- PDT, (Dejours,1993a, 2004, 1999/2007, 2012), a partir da discussão que o mesmo propõe sobre organização de trabalho, trabalho e mobilização subjetiva do sujeito ante esse trabalho real, através da inteligência astuciosa.

Para Dejours (2004), a relação entre trabalhador(a) e organização do trabalho é sempre geradora de desconfortos, impedimentos, constrangimentos, incongruências, pois de um lado, existem as prescrições, as regras, as figuras de poder, do outro, a história de vida, os hábitos, os valores, as necessidades individuais dos sujeitos.

De forma mais conceitual, a organização do trabalho pode ser entendida como a divisão das tarefas, que conduz alguns indivíduos a definir a partir de outros, o trabalho a ser executado, o modo operatório e os ritmos a seguir; e a divisão dos homens, ou seja, o dispositivo de hierarquia, de supervisão, de comando, que define e codifica todas as relações de trabalho (Dejours, Desors, \& Desriaux 1993).

Dessa forma, entende-se que as situações laborais em si, são dinâmicas. Assim como a vida, o cotidiano de trabalho é atravessado por imprevistos, acontecimentos que provém de diferentes fontes: máquinas, colegas de trabalho, chefia, espaço público, do(a) próprio(a) trabalhador(a).

O (a) trabalhador(a) será sempre confrontado com a distância que existe entre o prescrito e a realidade concreta da situação, e por isso, precisará mobilizar-se para alcançar os objetivos. Inclusive, esta compreensão estar presente em sua definição de trabalho: "é a atividade coordenada, desenvolvida por homens e mulheres para enfrentar aquilo que, em uma tarefa utilitária, não pode ser obtido pela execução estrita da organização prescrita" (Dejours, 2005, p. 43).

Nesse sentido, o autor, enuncia que o trabalho é, sobretudo, ação, concepção, mobilização. Ademais, sob tal compreensão, estabelece a ligação entre subjetividade e trabalho. Dejours (2012) esclarece que quando o(a) trabaIhador(a) se vê diante da lacuna irredutível entre tarefa e o real do mundo, o sofrimento inicial vivenciado, incita a necessidade de superação, e é justamente nesse momento que o(a) trabalhador(a) irá se utilizar da astúcia, da imaginação criadora, dos ajustamentos, para atuar sobre a realidade e encontrar as vias de transformação e resistência.

É nesse percurso que o trabalho se apropria da subjetividade, através da colhida da intuição, da engenhosidade do sujeito, mas é também dessa mobilização, chamada de inteligência prática ou astuciosa, que o próprio sujeito se transforma, através do acréscimo de novas habilidades, novas impressões afetivas, novas qualidades.

Embora a inteligência prática seja uma condição humana, ou seja, todos podem experimentá-la, ela pode ser afetada, a depender de algumas variáveis: o estado físico/psíquico do(a) trabalhador(a), se a tarefa faz sentido, as condições organizacionais e sociais em que terá que executar o trabalho. Assim, se pode falar de contextos de trabalho menos ou mais favoráveis à mobilização subjetiva e, portanto, ao desenvolvimento psicossocial dos sujeitos (Dejours, 2012).

Sobre os contextos de trabalho ou organizações favoráveis, o autor diz que são aquelas que possibilitam condições propícias, leia-se: condições de trabalho ou materiais, como por exemplo, ferramentas, instrumentos, estrutura física; e condições organizacionais existência de espaços de autonomia e criatividade no cotidiano de trabalho, relações de confiança e apoio. (Dejours, 2004; Dejours et, al. 1993).

Nessa perspectiva, o relacionamento entre organização do trabalho e sujeitos, continua sendo elemento decisivo para compreender a relação entre subjetividade e trabalho e, por conseguinte, as condutas, comportamentos, experiências de sofrimento e prazer vivenciadas nas situações laborais (Dejours, 1993a). Considerando tais premissas, procuramos conhecer e analisar as vivências subjetivas dos psicólogos do NASF, a partir da relação destes com a organização de trabalho e as condições em que desenvolvem a atividade em questão.

\section{Método}

\section{Participantes}

Participaram da pesquisa sete psicólogos, cujas idades variaram entre 29 e 53 anos, sendo a maioria do sexo feminino $(N=6)$, que faziam parte de equipes dos Núcleos de Apoio à Saúde da Família (NASF) de uma capital do Nordeste. Com relação ao tempo de trabalho no NASF, a maioria tem de dois a quatro anos, apenas 
dois ultrapassavam os seis anos. Quanto à ênfase de formação, predomina a clínica $(N=5)$. O processo de trabalho do NASF e a identificação com a lógica de trabalho da ESF aparecem como as principais motivações dos psicólogos para a entrada no NASF $(N=6)$.

\section{Instrumentos}

Os instrumentos utilizados na coleta de dados foram: questionário sóciodemográfico e roteiro de entrevista semiestruturado. O questionário sociodemográfico foi usado para ter acesso às informações individuais dos participantes, com perguntas de identificação, tais como: idade, sexo, tempo de trabalho, área de formação, motivação para trabalhar no NASF, entre outros, com intuito de caracterizar os participantes da pesquisa.

No tocante à "escolha" pela realização de entrevistas individuais, esta ocorreu mediante a recusa dos trabalhadores em participar de entrevistas em grupo. Eles explicaram que seria uma situação desconfortável e também difícil de conseguir, já que tinham dias muito corridos e atarefados. Contudo, entende-se que apesar da metodologia da PDT privilegiar os diálogos com grupos, o próprio Dejours percebe a necessidade de recorrer a entrevistas duais e individuais em situações específicas, como fora sinalizado por Dejours e Bègue (2010).

Entendemos, portanto, que, apesar de não utilizarmos a metodologia proposta por Dejours (1993b), respeitamos um dos elementos essenciais dos pressupostos teórico metodológicos do autor: a palavra como via privilegiada de acesso à subjetividade. Ao elegermos a subjetividade como aspecto primordial em nossa pesquisa, é necessário explicitarmos que ela engloba não só a realidade aparente, mas também aquela que, muitas vezes, não é percebida diretamente no cotidiano de trabalho. Assim, uma ferramenta básica em nossa pesquisa é a palavra, visto que ela é a única via de acesso a essa realidade que está subjacente. É a partir da palavra, portanto, que pesquisador e participante podem chegar à inteligibilidade do que ainda não estava acessível (Dejours, 1993a).

As questões do roteiro de entrevista foram construídas com base no referencial teórico e versavam sobre escolhas, motivações e possibilidades para o exercício da profissão, trabalho real, dificuldades e limitações no trabalho e relacionamento com os superiores.

\section{Procedimentos}

A aplicação do questionário sociodemográfico e da entrevista foi realizada ao mesmo tempo, de forma individual, no local de trabalho dos profissionais, com duração de aproximadamente 40 minutos. Para assegurar o anonimato dos participantes, optou-se pela sigla "P" de psicólogo(a), seguida de um número aleatório que diferencia cada participante. Uma vez que se tratam de sete entrevistados, os números vão de '01' a '07'. $O$ estudo seguiu todos os preceitos éticos relativos à pesquisa com seres humanos, tendo sido certificado pelo Comitê de Ética em Pesquisa (CEP).

\section{Análise dos Dados}

A análise dos dados foi feita segundo a análise de conteúdo categorial temática, proposta por Bardin (1977/2011), em que os textos das entrevistas passaram por operações de desmembramento em categorias conceituais e/ou subcategorias, segundo agrupamentos analógicos, o que exige considerar os discursos dos participantes, em um primeiro momento de forma individual e, posteriormente, como um todo.

\section{Resultados e discussão}

A partir da análise das entrevistas, emergiram as seguintes categorias temáticas: organização do trabalho e condições de trabalho. A primeira desdobra-se em três subcategorias: processo de trabalho, a gestão da secretaria de saúde, e ritmo de trabalho, tornando possível visualizar a organização formal e informal do trabalho dos psicólogos do NASF. A segunda, refere-se às condições em que estes profissionais desenvolvem as atividades, ou seja, os recursos presentes e/ou ausentes necessários ao seu fazer.

\section{Organização do Trabalho}

Nesta categoria, elucidam-se as atividades que os psicólogos do NASF desempenham em função das prescrições e das necessidades do dia-a-dia; a configuração do processo de trabalho; o ritmo que seguem para atender as demandas; a jornada de trabalho no tocante aos horários; quem são os dispositivos de gestão e o relacionamento existente entre estes e os psicólogos, bem como, as relações de trabalho decorrentes.

Com relação à subcategoria processo de trabalho, as falas dos participantes trouxeram as responsabilidades que eles têm, segundo a configuração de seu trabaIho. De acordo com os profissionais, cabe aos psicólogos a realização de escutas, orientação, interconsulta, visitas domiciliares, trabalho com grupos operativos; por exemplo, palestras para hipertensos, participação na construção e implementação de projetos singulares terapêuticos (PST), atenção ao cuidador, que vai desde a 
parte de avaliação psicológica, escuta individual, orientação, mediação de conflitos, até o suporte técnico na condução e resolução de diversas demandas, principalmente as que envolvem questões de saúde mental. Portanto, é de sua responsabilidade o apoio assistencial e técnico-pedagógico às EqSF de seu território de atuação, visando o aumento da resolutividade e da qualidade das práticas de promoção e prevenção à saúde por elas desenvolvidas e/ou oferecidas.

Além disso, os psicólogos, na realidade pesquisada, também eram responsabilizados pela gestão administrativa das Unidades de Saúde da Família (USFs). Sendo assim, em seu cotidiano de trabalho, os profissionais realizam também: o controle de todo o material de trabalho usado para o funcionamento da USF, desde medicamentos a luvas e seringas, controle de faltas e carga horária de trabalho dos profissionais, regulação de exames e consultas, avaliação de desempenho da equipe da unidade, ou seja, toda a parte burocrática e administrativa, assumindo, portanto, o papel de representantes diretos da diretoria/gestão, tanto para os profissionais da USF, como para os usuários. Sobre esta configuração do processo de trabalho do NASF, os psicólogos relatam que a divisão de seu trabalho é bastante complexa, pois envolve atividade de diferentes âmbitos, como é possível observar no relato do(a) profissional a seguir:

O apoio matricial é o que dá suporte na unidade, vê o que tá faltando, vê estoque de medicação; tem que controlar a farmácia, tem que controlar a pauta de funcionários... E a outra que é a propriamente do NASF mesmo, que é a de assistência, dentro da sua formação, fazer as avaliações, acompanhamento de casos... Atender no caso a família, a parte de saúde da família (P02).

No relato, fica claro o posicionamento dos psicólogos frente à configuração adotada de seu processo de trabalho. De um lado, estão as tarefas que eles denominam como referentes ao NASF, as quais eles chamam de "parte assistencial", ou seja, as tarefas relacionadas ao apoio assistencial e técnico-pedagógico prestado às equipes das USFs no desenvolvimento das práticas de promoção e prevenção da saúde. Do outro lado, estão as tarefas relacionadas à gerência da unidade, entendidas como o "apoio matricial".

Sobre estas informações, chama-se atenção para duas questões: a compreensão e configuração municipal adotada de apoio matricial e como isso reverbera na relação entre os psicólogos (equipe NASF) e profissionais da unidade (equipe USF). Pode-se observar nas entrevistas que o apoio matricial realizado tem face muito particular, está ligado, sobretudo, à gestão administrativa da unidade, ou seja, ao gerenciamento da atenção à saúde dada neste nível de cuidado. Assim, os psicólogos (equipe NASF), tornam-se para as EqSFs, representantes da gestão.

Essa configuração de apoio matricial afasta-se da proposta do Ministério da Saúde, que pelo menos no que diz respeito ao ideal, aposta na retaguarda assistencial e técnico-pedagógica dada pelas equipes do NASF como uma forma de aumentar a resolutividade do trabalho da ESF, através do estabelecimento de cooperação e coresponsabilização entre as duas equipes (MS, 2009).

De acordo com Medeiros (2015), quando a lógica do encontro matricial submete as equipes da ESF ao protagonismo da "expertise" ou da tutela de seus apoiadores, esta se mostra inadequada, sendo signo da insistência da verticalização da organização do cuidado em saúde. Nesse sentido, o matriciamento como estratégia de articulação e gestão em rede fica prejudicado, quando o elemento horizontal de organização do trabalho, de oferta dos serviços e práticas entre as duas equipes está comprometido.

Ainda a respeito dessa diferenciação entre as práticas consideradas do NASF e as práticas entendidas como apoio matricial/gerência da unidade, os psicólogos não reconhecem a função administrativa como uma atuação cabível com a formação ou papel do(a) psicólogo(a), enquanto especialista. Fazem, assim, uma distinção clara de quando estão no lugar de apoiador(a) (gestor/gestora) e de psicólogo(a) (especialista), como fica evidente no relato do(a) participante P06: "nós temos a parte administrativa, toda a parte profissional, de falta, de administração, tudo. E a parte de Psicologia, as escutas qualificadas, os grupos operativos, visitas, interconsultas".

Faz-se necessário refletirmos sobre que tipo de suporte matricial é esse que está sendo proposto como lógica de trabalho para os psicólogos como integrantes da equipe NASF, e se essa configuração adotada tem contribuído para que este profissional possa, de fato, atender à proposta ministerial de prestar uma retaguarda especializada às EqSF. No entanto, cabe aqui, também, problematizar esse estranhamento dos profissionais em ocupar lugares de gestão, especificamente nos espaços de atuação criados pelas políticas públicas.

Em pesquisa de levantamento realizada pelo Conselho Federal de Psicologia - CFP e Centro de Referência Técnica em Psicologia e Políticas Públicas CREPOP (2010), as práticas dos psicólogos no campo da 
atenção básica à saúde são marcadas por grande diversidade, pois variam conforme o local de implementação da política específica, bem como, segundo as necessidades de cada região. As ações desenvolvidas pertencem a diferentes âmbitos de atuação: gestão de serviços; docência; e atenção aos usuários e familiares. Outrossim, é considerado que a inserção do(a) psicólogo(a) na atenção básica abre um leque de possibilidades, mas que destas emergem dificuldades para os profissionais, que julgam não se sentirem capacitados.

Entende-se que, mediante a herança de uma formação que, durante muito tempo, focou na interpretação da vida íntima, em que os aspectos intrapsíquicos eram a principal preocupação dos psicólogos e os consultórios o principal lugar de atuação/intervenção desses profissionais, criou-se estigmais, como, por exemplo, o fato de ligarem o profissional de psicologia ao divã. Tal herança resultou na construção de muitas das representações que a sociedade tem desses profissionais e das próprias referencias de práticas e identidade profissional dos psicólogos (Azevedo \& Kind, 2013).

Quanto ao dispositivo de comando, de supervisão, representado aqui pela subcategoria gestão da secretaria de saúde, representada pelos diretores dos distritos sanitários, as falas dos participantes elucidam como são as relações entre estes profissionais e os diretores, e como elas interferem na execução da atividade. Os psicólogos relatam que a gestão ou seus supervisores pouco favorecem a dinamicidade e deslocamentos necessários às situações de trabalho. Como podemos observar no relado do(a) participante P07:

Como eu quero contratar você, se eu não dou autonomia, você tem que fazer algo para mostrar aparência, então essa forma aí, muitas vezes, influência no processo de trabalho, e você termina não fazendo, porque sabe que tem que cumprir isso. Pelo menos na minha visão de clima e de cultura organizacional, ele não saiu daquela questão de você desenvolver pessoas né, acorrenta aquela pessoa a fazer isso, é meio escravista.

O contexto de trabalho na atenção básica é repleto de imprevistos e necessidades de ajustes constantes. A falta de autonomia que emergiu nos relatos dos participantes acentua a irredutível distância entre o que é prescrito e a situação concreta, pois o(a) trabalhador(a) necessita diariamente fazer escolhas, ajustes, tomar decisões diante das variabilidades, principalmente nessa configuração de trabalho aqui relatada, onde o(a) psicólogo(a) também gerencia as USFs.
Contudo, diante de uma gestão rígida vê-se impedido ou até mesmo passivo.

Dejours (1994) ressalta que o espaço possível de transação entre o sujeito, a organização prescrita e o outro (patrão, supervisor, colegas, clientes) é decisivo para propiciar a mobilização subjetiva necessária às situações de trabalho. Pois, diante da falta de autonomia, toda a dinâmica de transformação do sofrimento inicialmente sentido pela confrontação com os obstáculos, fica comprometida.

Além de ter consequências para a própria organização do trabalho, pois Dejours (2004), alerta que, nas situações laborais em que o controle e a vigilância dos gestos, dos movimentos, são acentuados, rigorosos ou severos, favorece-se o surgimento de vias fortemente diferenciadas em saber-fazer e técnicas individuais que tendem a permanecer na clandestinidade, capaz de gerar uma crise em diversas esferas do trabaIho, como na gestão, na coesão do coletivo de trabalho e na produção em si.

Lembremos que, como os psicólogos relatam terem tarefas referentes à parte administrativa das USFs, eles acabam tendo que responder pelos eventuais problemas que comprometem o adequado funcionamento das unidades de saúde. Como dito anteriormente, o controle de faltas também fica sob responsabilização desses profissionais. Eles, muitas vezes, veem-se em um dilema, pois têm que cobrar presença e marcar falta dos próprios colegas de trabalho, com quem dividem o cotidiano. Condição explicitada na fala do(a) P07: "Quando a gente tem autonomia para fazer é melhor... mas, se for de regra, muitas vezes, tem que pedir o atestado, uma declaração, se não tem que colocar falta, e isso gera mais uma revolta naquele funcionário. "

Nesse trecho, fica nítido como ter que seguir as normativas deixa os psicólogos em uma situação desconfortável, porque eles precisam gerir os recursos materiais e imateriais, e isso lhes exige, muitas vezes, indisporem-se com os colegas, o que inevitavelmente afeta as relações de trabalho e toda uma intenção de se trabalhar em conjunto, que é a proposta de apoio matricial e matriciamento pensada para a ESF/NASF.

Ainda sobre os seus gestores ou supervisores, os profissionais evidenciam a fragilidade ou inexistência de apoio na resolução e compartilhamento das responsabilidades pelas demandas administrativas das USFs. Situação elencada no relato do(a) participante P07:

É ter mesmo essa questão de apoio de gestão, de pessoas competentes mesmo, que possam 
entender e tá junto, e, em vez de dizer, "faça", dizer: "vamos fazer". É diferente, a questão de pegar ali e tá presente. É preciso uma gestão mais humanizada na rede, para poder fazer com que as coisas funcionem melhor, você recebe uma coisa, você pode dar né?! Se a própria gestão fosse articulada no sentido de parar e escutar até quem tá na ponta, e cuidar de quem tá na ponta, você conseguiria gerar uma onda bem mais intensa. Eu quero coisa que dêr um apoio para eu poder desenvolver o trabalho.

A dimensão administrativa do trabalho dos psicólogos do NASF coloca-os em uma posição de gestores para as EqSFs e de mediadores entre gestão da secretaria de saúde e funcionários das USFs/usuários. Portanto, diariamente esses profissionais lidam com as exigências de seus supervisores de um lado e do outro, com as cobranças dos funcionários das USFs e usuários. Tendo, assim, que responderem, muitas vezes, por situações que decorrem da escassez de recursos, ou que, sobre as quais, não têm possibilidades reais de resolverem, já que se referem a questões muito gerais, como o repasse de verbas, salário, distribuição de medicação.

Em meio a essa conjuntura de trabalho, é inevitável que surja a necessidade dos profissionais de recorrerem aos seus supervisores, à secretaria de saúde, esperando ter apoio, serem ouvidos, compreendidos, ajudados. Contudo, os psicólogos apontam a falha no entendimento e no envolvimento de seus gestores com tais necessidades, fruto de problemas na comunicação, necessária para que essas questões venham a ser discutidas.

De acordo com Dejours (1994), ao tocar no tema das relações intersubjetivas para a evolução da organização do trabalho, a questão da harmonia e do entendimento entre os protagonistas torna-se de igual importância. Do ponto de vista desse autor, a existência de um espaço de entendimento, apesar de ser sempre insuficiente e imperfeito, visto que as situações de trabalho estão sempre em contínuo movimento e transformação, é sempre possível e desejável.

Como ponto de partida, julga-se ser necessário que as relações hierárquicas sejam superadas, pois é preciso que a gestão da secretaria de saúde, aqui representada pelos diretores dos distritos sanitários, tenham a consciência e assumam que não sabem de tudo de antemão e estejam prontos para ouvir o discurso dos trabalhadores sem fazer distinção, já que são eles que contribuem verdadeiramente para a organização do trabalho e/ou serviço. Por outro lado, aqueles que necessitam falar, sejam ousados, já que há sempre um risco em dizer aquilo que se pensa ou se faz, principalmente quando tomam decisões que se afastam das prescrições, o que é bastante comum, como é o caso da realidade de trabalho desses profissionais. Só assim, caminha-se em direção à criação de espaços de diálogo, onde há troca de informações e de aconselhamentos sobre aspectos essenciais do trabalho (Dejours, 1994).

A respeito da frequência em que a atividade dos psicólogos se desenvolve, ou seja, o ritmo de trabalho, os relatos dos participantes leva-nos a compreender que o cotidiano de trabalho desses profissionais, por vezes, é bastante intenso. São muitos os momentos de agitação, de variações, vivenciados por eles. Inclusive, os psicólogos tiveram dificuldades em diferenciar um dia habitual e um dia intenso de trabalho. Como podemos observar na fala do(a) participante (P05): "Então, não sei, se eu consigo diferenciar, mas todo dia... qual o dia que não seja intenso?"

Os trabalhadores atribuem a sobrecarga de trabaIho ao acúmulo de funções (NASF e gerência), pois essa sobreposição gera muitas demandas ao longo do dia. Como ilustra o seguinte trecho:

Um dia de trabalho intenso pra gente, principalmente na parte administrativa, é quando falta algum profissional... às vezes, falta material ou a organização do material que chega, a gente vai passando pelos setores, toda essa logística da unidade, é muito intenso, todos os dias é mais ou menos assim. (P04).

Então, é possível identificar no cotidiano de trabalho desses profissionais que eles precisam ser ágeis, estarem sempre atentos e precavidos, para tomar decisões, dar informações, identificar e corrigir erros em pequenos intervalos de tempo. Apesar desse tempo não ser imposto diretamente, por exemplo, pela hierarquia, este acaba sendo controlado indiretamente pelo ritmo de funcionamento da USF, que como vimos é geralmente muito intenso, e os psicólogos acabam tendo que realizar movimentos com certa rapidez e velocidade para poder executar sua atividade.

Dejours (1999/2007) destaca sobre a ação das pressões do ritmo de trabalho no corpo dos trabalhadores. As situações de trabalho consideradas repetitivas ou extenuantes são pontualmente uma ameaça à construção da saúde no trabalho, uma vez que acarretam a fadiga, o desgaste, além de favorecer a ocorrência de acidentes de trabalho e a alienação, por exemplo, pela auto aceleração. 
Destaca-se ainda que - apesar de cada categoria profissional estar submetida a um modelo específico de organização formal do trabalho, ou seja, a uma divisão do trabalho, com objetivos fixados, prescrições, sistema hierárquico, modalidades de comando - a relação entre organização do trabalho e trabalhadores não é um bloco rígido. A estabilidade aparente de tal relação está assentada em um equilíbrio livre e aberto à evolução e às transformações (Dejours, 1993; Dejours, Abdoucheli, \& Jayet, 1994/2011). O que explica, por exemplo, a continuidade do trabalho dos psicólogos, por meio da mobilização subjetiva, mesmo diante de uma organização formal do trabalho não favorável e também nos permite pensar em mudanças das situações aqui elucidadas.

\section{Condições de Trabalho}

A categoria anunciada contempla as condições em que os psicólogos desenvolvem suas práticas e ações. Refere-se a tudo aquilo que envolve o posto de trabalho, os materiais fornecidos ou não, para realizarem a atividade, é o ambiente físico, químico ou biológico das situações laborais. De acordo com Dejours (2012), as condições de trabalho têm grande importância para a compreensão dos impactos do trabalho sobre o corpo, podendo ocasionar desgaste, fadiga e doenças somáticas.

No conteúdo analisado, os psicólogos avaliam suas condições de trabalho como escassas e precárias, apontando alguns problemas como a inadequada e insuficiente estrutura física das USFs, como se pode observar na fala a seguir: "Nós não temos sala para trabalhar... a gente fica usando uma sala que vai sobrando. Nós não temos salas para trabalhar com grupos e para trabalho individual também não" (P05).

É nítida a preocupação dos profissionais com essa questão das salas, justamente porque se torna uma barreira para a realização de seu trabalho. Eles reclamam que a estrutura física da maioria das UFSs ainda não se adaptou ao novo processo de trabalho, que, atualmente, conta com número maior de profissionais diversificados e, portanto, fornece atendimentos diferenciados, como a própria escuta psicológica - seja para o usuário ou para os integrantes da equipe -, o trabalho em grupo e também a parte da administração, que inevitavelmente requer dos psicólogos a utilização de uma sala para realizar o preenchimento de fichas, o manuseio e preparação de documentos, por exemplo.

Essa constatação da precariedade das condições de trabalho feitas pelos profissionais parece ser um problema que não se restringe a uma situação local ou específica de trabalho, pois, como cita Assunção e Filho (2011), as condições de trabalho no setor de saúde pública, na maioria das vezes, são adversas, com recursos físicos e materiais reduzidos ou ausentes, salários rebaixados, ausência de planos de cargos e ascensão na carreira, baixa valorização do trabalho por parte da gestão e população. Aspectos estes que podem ser observados em vários relatos dos psicólogos a respeito das condições em que desenvolvem seu trabalho.

Por conta, dessa questão estrutural da USFs, os trabalhadores fazem adaptações e manobras para alcançar os objetivos e atender às demandas. Muitos relatam recorrerem às salas que no momento estão sem atendimento, por exemplo, quando é um dia de menor fluxo ou quando faltam profissionais. Tal conjuntura demonstra como ocorre a mobilização subjetiva no trabalho via inteligência prática. Os trabalhadores engajam-se na busca por alternativas, criam novas formas de executar as ações, mediante os impedimentos que se apresentam.

E é justamente esse engajamento aqui relatado e que será observado em toda a discussão da categoria, ou seja, as adaptações e manobras feitas, que se pode compreender o comprometimento que eles têm com o serviço, com sua profissão, pois mesmo diante de uma organização de trabalho que pouco favorece a resolutividade das questões diárias, seja pelo acúmulo de funções, da rigidez e falta de apoio da gestão, os psicólogos em algum momento conseguem lançar mão da criatividade e da astúcia para viabilizar o seu trabalho. Essa situação elucida, bem a colocação de Dejours (2005), quando diz que todo trabalho está sempre situado na subjetividade.

Entretanto, não se pode deixar de pontuar que essa prática da "utilização da sala disponível", por conta da falta de salas propícias para o tipo de atendimento e/ou atividade por esse profissional realizado, pode lhe expor a alguns riscos, principalmente ao biológico, já que a maioria das salas contém materiais perfurocortantes e são ambientes em que há a presença de material biológico.

Outra preocupação dos trabalhadores no tocante às condições de trabalho é a falta de instrumentos e/ou materiais de trabalho. Como podemos observar no seguinte relato:

Nem sempre a gente tem material lúdico pra trabalhar com criança, então, muitas vezes, quando a gente quer fazer um trabalho voltado para criança, a gente tira dinheiro do bolso pra poder comprar tinta, pra poder comprar brinquedo, ou algum material específico para fazer algo coletivo (P02). 
Novamente, se observa os impactos que a escassez ou falta de recursos têm para o desenvolvimento das ações e da qualidade do que é ofertado. Sabe-se que o trabalho na atenção básica é pensado para alcançar toda a família, com o objetivo de não só tratar, mas de prevenir doenças e promover saúde. Nesse sentido, as práticas dos profissionais desse nível de atenção devem contemplar a atenção à saúde de todas as faixas etárias, em nível individual e coletivo, e não diferentemente dos demais, os psicólogos almejam tal objetivo.

Contudo, os entrevistados apontam que existe uma defasagem entre as prescrições do trabalho e a situação concreta, principalmente referente às condições de trabaIho. Ou seja, há objetivos fixados, formas de fazer, ações a serem desenvolvidas, mas na prática é feito o possível diante dos problemas enfrentados. Assim, mais uma vez, emerge a importância de se dar voz aos trabalhadores como via de conhecimento da verdadeira face do trabaIho, aquilo que é feito, aquilo que se acrescenta, ou o que é dado de si mesmo para dar conta das lacunas existentes, ou seja, para se ter acesso ao trabalho real (Dejours, 2012).

Ademais, os psicólogos ainda relatam que a precarização de suas condições de trabalho afeta a realização das visitas domiciliares, que é outra prática bem característica do processo de trabalho dos psicólogos do NASF, segundo as orientações ministeriais. Como ilustra a fala do(a) participante P07: "Ter acessibilidade a alguns recursos, originalmente tinha um carro que ficava à disposição... e a questão de poder se deslocar de um lado para o outro, porque, às vezes, fica custoso para a gente, né! ". Como não existe um carro cedido à equipe do NASF ou da USF, os psicólogos têm que realizar as visitas em seus carros. Sobre essa questão, os participantes da pesquisa elucidaram que o dinheiro gasto com gasolina não é custeado pela secretaria e como existem algumas áreas de difícil acesso, acaba-se danificando o carro, podendo, assim, gerar maiores custos para eles.

A questão salarial e o vínculo empregatício também apareceram como algo que deixa a desejar. Os profissionais dizem-se insatisfeitos, principalmente porque julgam que o salário recebido é aquém do esperado e do justo, levando em consideração o número de responsabilidades e da carga de trabalho que possuem. Isso pode ser observado no relato do(a) participante P01: "Bem que o salário poderia ser um pouquinho melhor, porque a gente trabalha... trabalha muito, e a questão também, assim, como eu já falei, de ocupar de alguma forma, dois cargos".
Em relação ao vínculo empregatício, a instabilidade do mesmo se sobressai nos discursos, bem como ficam evidentes os impactos que tem para a realização de um bom trabalho. A maioria dos psicólogos entrevistados são prestadores de serviço, ou seja, a ligação com a secretaria de saúde/município se dá por contratos de tempo determinado, que podem ser renovados ou não. A instabilidade do vínculo empregatício manifesta-se nos profissionais como incerteza, preocupação, angústia, sentimentos possíveis de serem percebidos no relato de P02: "O vínculo nosso, ele é bem instável, um dia a gente pode tá aqui e o outro não, tem essa instabilidade"; ou ainda no relato do(a) participante P04: "O vínculo empregatício, a gente sabe que deixa muito a desejar, prestador de serviço, o vínculo realmente é hoje e não é amanhã".

A desvalorização salarial e a flexibilização dos vínculos de trabalho fazem parte da nova morfologia social do trabalho. É a precarização das situações de trabalho que surge com a reestruturação produtiva (Alves, 2011), ou seja, fazem parte de uma conjuntura maior; são pressões externas, porém vão sendo impregnadas de conteúdo afetivo, como podemos observar no caso dos psicólogos, quando experimentadas no cotidiano do trabalhar. Para Dejours (1994), a nova Divisão Internacional do Trabalho tem levado a uma grande desestruturação das trajetórias profissionais, sendo assim, um golpe "invisível" na saúde.

Antunes e Druck (2015), por exemplo, destacam que a reestruturação produtiva iniciada a partir do final da década de 1960, como uma estratégia do capital para recuperar seu ciclo reprodutivo, vem impulsionando modos diferenciados de precarização do trabalho, e que no Brasil, essa condição pode ser observada em especial (mas não só) no setor de serviços. Esse processo tendencial de precarização é marcado pelo aumento do trabalho submetido a contratações temporárias, sem estabilidade, sem registro em carteira, salários baixíssimos, intensificação da jornada de trabalho, assumindo, assim, relações e formas de trabalho semelhantes à feição informal. Ademais, os trabalhadores submetidos a tal conjuntura de trabaIho estão mais vulneráveis a acidentes, adoecimento, assédio moral, desproteção social.

\section{Considerações finais}

O objetivo deste estudo foi analisar a organização e as condições de trabalho de psicólogos dos NASFs. Para tanto, buscou-se lançar luz sobre o cotidiano de 
trabalho desses profissionais, privilegiando o ponto de vista do(a) trabalhador(a), que detém, de fato, o conhecimento de sua atividade.

As vivências elucidadas pelos participantes refletem um cotidiano de trabalho marcado por alta carga de trabalho, diversas pressões, ritmo de trabalho extenuante, pouca autonomia, relações intersubjetivas de poder e conflituosas e precarização das condições de trabalho, que acentuam as dificuldades e imprevisibilidades das situações de trabalho. Dessa maneira, os aspectos evidenciados permitem-nos compreender e analisar como a organização e as condições de trabalho estão diretamente ligadas à possibilidade/impossibilidade de desenvolvimento no e pelo trabalho, via mobilização subjetiva, bem como, ao alcance da oferta de um serviço mais próximo dos objetivos fixados.

Chama-se atenção ainda para o comprometimento que os profissionais têm com o seu trabalho, pois mesmo diante de condições não favoráveis aos ajustamentos e manobras requeridas pelas situações laborais, os psicólogos, em alguns momentos fazem esforços, são inventivos para atenderem as demandas e garantir a continuidade das ações/serviços. Contudo, é necessário que haja mudanças nas situações de trabalho, haja vista, a necessidade de não quebrar essa mobilização ou de favorecê-la, bem como, de propiciar o melhoramento do cuidado ofertado.

Destaca-se também, a pertinência de uma reflexão mais aprofundada sobre a configuração de trabalho do NASF adotada pelo município, pois julga-se necessário avaliar de que forma tem contribuído para que esse profissional atenda às reais necessidades da população e às perspectivas iniciais que respaldaram a abertura dada a Psicologia nesse âmbito de cuidado. Ademais, associada a uma visão crítica dos modelos de atuação e identidade profissional historicamente construído e do lugar das instituições formadoras na manutenção ou evolução desses modelos. Pois, a convocação dos psicólogos nos serviços públicos de saúde não se restringe a ser meros executores da política pública específica, mas também profissionais capazes de contribuírem na elaboração e avaliação e/ou gestão da mesma.

Sabe-se que a análise do(a) homem/mulher em situações de trabalho é bastante complexa e, por vezes, resultado de múltiplos determinantes. Por isso, acredita-se que as análises e as conclusões feitas não esgotam as discussões acerca da temática; assim, espera-se inspirar novos estudos que deem continuidade à investigação da inserção dos profissionais de Psicologia em novos espaços de atuação, a partir da perspectiva da Psicologia do Trabalho e que superem ou forneçam alternativas às limitações deste estudo, a exemplo da impossibilidade de realizar entrevistas em grupo.

No mais, é possível afirmar que este estudo prestou uma contribuição científica e social, uma vez que descortina sob o olhar da Psicologia do Trabalho a organização e as condições de trabalho do(a) psicólogo(a) do NASF. São profissionais que, embora sejam recentes como força de trabalho na atenção básica, já ocupam importante lugar para o processo de cuidado nesse nível de atenção.

Entende-se, assim, que as reflexões e conclusões deste estudo remetem-nos para a urgência de dar uma maior visibilidade à atividade dos psicólogos dos NASFs, tendo em vista que isso também significa preocupar-se com o cuidado prestado. E também para a consideração de que são as articulações entre o social, a política, a economia e as subjetividades, que configuram a singularidade das questões de trabalho.

\section{Referências}

Alves, G. (2011). Trabalho e Subjetividade- o espirito do toyotismo na era do capitalismo manipulatório. O Social em Questão, 25(26), 481-488. Recuperado de http://osocialemquestao.ser.puc-rio.br/ media/24_OSQ_25_26_Ribeiro.pdf

Antunes. R., \& Druck, G. (2015). A terceirização sem limites: a precarização do trabalho como regra. O Social em Questão, 28(34), 19-40. doi: 10.1590/0102-311X00146315

Assunção, A. A., \& Filho, J. M. J. (2011). Transformações do trabalho no setor saúde e condições para cuidar. In A. A. Assunção \& A. A. Brito (Orgs.), Trabalhar na saúde: experiências cotidianas e desafios para a gestão do trabalho e do emprego (pp. 45-65). Rio de Janeiro: Fiocruz.

Azevedo, N. S., \& Kind, L. (2013). Psicologia nos Núcleos de Apoio à Saúde da Família em Belo Horizonte. Psicologia: Ciência e Profissão, 33(3), 520-535. doi: 10.1590/S1414-98932013000300002

Bardin, L. (2011). Análise de conteúdo. (3a edição, L. A. R, Augusto, Trad.). São Paulo: Edições 70. (Obra original publicada em 1977)

Bispo Júnior, J. P., \& Moreira, D. C. (2017). Educação permanente e apoio matricial: formação, vivências e práticas dos profissionais dos Núcleos de Apoio à Saúde da Família e das equipes apoiadas. Cadernos de Saúde Pública, 33(9). doi: 10.1590/0102-311x00108116

Böing, E., \& Crepaldi, M. A. (2010). O psicólogo na atenção básica: uma incursão pelas políticas públicas de saúde brasileiras. Psicologia: Ciência e Profissão, 30(3), 634-649. doi: 10.1590/ S1414-98932010000300014

Camargo-Borges, C., \& Cardoso, C. L. (2005). A psicologia e a estratégia saúde da família: compondo saberes e fazeres. Psicologia \& Sociedade, 17(2), 26-32. doi: 10.1590/S0102-71822005000200005

Cezar, P. K., Rodrigues, P. M., \& Arpini, D. M. (2015). A psicologia na estratégia de saúde da família: vivências da residência multiprofissional. Psicologia: Ciência e Profissão, 35(1), 211-224. doi: 10.1590/1982-3703000012014 
Conselho Federal de Psicologia \& Centro de Referência Técnica em Psicologia e Políticas Públicas (Orgs.). (2010). Práticas de psicólogose psicólogas na atenção básica à saúde. Brasília: Brasília Rádio Center.

Dejours, C. (1993a). Addendum: da psicopatologia à psicodinâmica do trabalho. In S. Lancman \& L. L. Sznelwar (Orgs), Cristopher Dejours: da psicopatologia à psicodinâmica do trabalho (pp. 47-104). Rio de Janeiro/Brasília: Fiocruz/Paralelo 15.

Dejours, C. (1993b). A metodologia em psicologia do trabalho. In S. Lancman \& L. L. Sznelwar (Orgs), Cristopher Dejours: da psicopatologia à psicodinâmica do trabalho (pp. 105-126). Rio de Janeiro/ Brasília: Fiocruz/Paralelo 15.

Dejours, C. (1994). Entre sofrimento e reapropriação: o sentido do trabalho. In S. Lancman \& L. L. Sznelwar (Orgs), Cristopher Dejours: da psicopatologia à psicodinâmica do trabalho (pp. 433-448). Rio de Janeiro/ Brasília: Fiocruz/Paralelo 15.

Dejours, C. (2004). Subjetividade, trabalho e ação. Revista Produção, 14(3), 27-34. doi: 10.1590/S0103-65132004000300004

Dejours, C. (2005). O fator humano. (5 $5^{a}$ ed., M. I. Stocco Beitol \& M. J. Tonelli, Trads.). Rio de Janeiro: FGV.

Dejours, C. (2007). A banalização da injustiça social. (7 ${ }^{\text {a }}$ ed., L. A. Monjardim, Trad.). Rio de Janiero: FGV. (Obra original publicada em 1999)

Dejours, C. (2012). Sexualidade e trabalho. (F. Soudant, Trad.). Brasília: Paralelo 15.

Dejours, C., Abdoucheli, E., \& Jayet. C. (2011). Psicodinâmica do trabaIho: contribuições da escola Dejouriana à análise da relação prazer, sofrimento e trabalho. (M. I. S. Betiol, Trad.). São Paulo, SP: Atlas. (Obra original publicada em 1994)

Dejours, C., \& Bègue, F. (2010). Suicídio e trabalho: o que fazer? Brasília: Paralelo.

Dejours, C., Desors, D, \& Desriaux, F. (1993). Por um trabalho, fator equilíbrio. Revista de Administração de Empresas -RAE, 33(3), 98-104. Recuperado de http://www.scielo.br/pdf/rae/v33n3/a09v33n3

Franco, T. B., \& Merhy, E. E. (2012). Cartografias do trabalho e cuidado em saúde. Tempus Actas de Saúde Coletiva, 6(2), 151-163. doi:10.18569/tempus.v6i2.1120

Freire, F. M. S., \& Pichelli, A. A. W. S. (2013). O Psicólogo apoiador matricial: percepções e práticas na atenção básica. Psicologia Ciência e Profissão, 33(1), 162-173. doi: 10.1590/ S1414-98932013000100013

Garcia, C. A.S. J., \& Nascimento, P.T. A. (2012). O dispositivo de apoio matricial na atenção primária em saúde: um relato de experiência no município de João Pessoa-PB. Revista Saúde Pública, 5(2), 93-104. doi: 10.1590/S1414-462X2013000200018

Giacomozzi, A. I. (2012). A Inserção do Psicólogo na Estratégia de Saúde da Família ea Transição de Paradigma em Saúde. Psico, 43(3), 3. Recuperado de http://revistaseletronicas.pucrs.br/revistapsico/ojs/index.php/revistapsico/article/view/7212 AlnsercaoD oPsicologoNaEstrategiaDeSaudeDaFamiliaEA-5631410\%20.pdf

Gorayeb, R., Borges, C. D., \& Oliveira, C. M. D. (2012). Psicología en la atención primaria: acciones y reflexiones en programa de perfeccionamiento profesional. Psicologia: Ciência e Profissão, 32(3), 674-685. doi: 10.1590/S1414-98932012000300012

Katsurayama, M., Parente, R. C. P, Moraes, R. D., \& Moretti, R. O.P. (2013) Trabalho e sofrimento psíquico na Estratégia de Saúde da Família: uma perspectiva Djouriana. Cadernos Saúde Coletiva, 21(4), 414-419. doi: 10.1590/S1414-462X2013000400009

Leite, D. C., Andrade, A. B., \& Bosi, M. L. M. (2013). A inserção da Psicologia nos Núcleos de Apoio à Saúde da Família. Physis: Revista de Saúde Coletiva, 23, 1167-1187. Recuperado de https://www.scielosp.org/pdf/ physis/2013.v23n4/1167-1187/pt

Ministério da Saúde (2009). Secretaria de Atenção à Saúde, Departamento de Atenção Básica Cadernos de Atenção Básica: Diretrizes do NASFNúcleo de Apoio à Saúde da Família. Recuperado de http://bvsms. saude.gov.br/bvs/publicacoes/caderno_atencao_basica_diretrizes_ nasf.pdf

Ministério da Saúde (2012). Secretaria de Atenção à Saúde, Departamento de Atenção Básica Política Nacional de Atenção Básica. Recuperado de http://189.28.128.100/dab/docs/publicacoes/geral/pnab.pdf

Medeiros, R. H. A. (2015). Uma noção de matriciamento que merece ser resgatada para o encontro colaborativo entre equipes de saúde e serviços no SUS. Physis Revista de Saúde Coletiva, 25(4), 1165-1184 doi: 10.1590/S0103-73312015000400007

Moreira, D. D. J., \& Castro, M. G. D. (2009). O Núcleo de Apoio à Saúde Da Família (NASF) como porta de entrada oficial do psicólogo na atenção básica. TransFormações em Psicologia (online), 2(2), 51-64 Recuperado de http://pepsic.bvsalud.org/scielo.php?script=sci_arttext\&pid=S2176-106X2009000200003\&lng=pt\&tIng=pt

Portaria no 154, de 24 de janeiro de 2008 (2008, 24 de janeiro). Cria os Núcleos de Apoio à Saúde da Família - NASF. Diário Oficial da União, seção 1. Brasília, DF: Ministério da Saúde.

Silveria, A. F., Gewehr, C., Bonin, L. F. R., \& Bulgacov, Y. L. M (Orgs) (2008). Cidadania e participação social. Rio de Janeiro: Edelstein de Pesquisas Sociais.

Maria do Socorro Roberto de Lucena, Mestre em Psicologia da Saúde pela Universidade Estadual da Paraíba - UEPB,

Doutoranda no Programa de Pós-Graduação em

Psicologia Social pela Universidade Federal da Paraíba - UFPB. Endereço para correspondência: Rua Jociara Telino, 370, apt 401, bl 10, Jardim São Paulo - João Pessoa-PB, CEP: 58053-100. Telefone: (83)999323306. Email: marialucena.ms@hotmail.com

Thaís Augusta Cunha de Oliveira Máximo, Doutora em Psicologia Social pela Universidade Federal da Paraíba - UFPB, é Professora Adjunta da Universidade Federal da Paraíba - UFPB. Email: thaisaugusta@gmail.com

Recebido em 11.jan.18 Revisado em 29.set.19 Aceito em 31.dez.19 